\title{
An Alternative Approach to Decellularize Whole Porcine Heart
}

\author{
Ketaki Methe, Henrik Bäckdahl, ${ }^{2}$ Bengt R. Johansson, ${ }^{3}$ \\ Nikhil Nayakawde, Goran Dellgren, ${ }^{4}$ and Suchitra Sumitran-Holgersson ${ }^{1}$
}

\begin{abstract}
Scaffold characteristics are decisive for repopulating the acellular tissue with cells. A method to produce such a scaffold from intact organ requires a customized decellularization protocol. Here, we have decellularized whole, intact porcine hearts by serial perfusion and agitation of hypotonic solution, an ionic detergent (4\% sodium deoxycholate), and a nonionic detergent (1\% Triton X-100). The resultant matrix was characterized for its degree of decellularization, morphological and functional integrity. The protocol used resulted in extensive decellularization of the cardiac tissue, but the cytoskeletal elements (contractile apparatus) of cardiomyocytes remained largely unaffected by the procedure although their membranous organelles were completely absent. Further, several residual angiogenic growth factors were found to be present in the decellularized tissue.
\end{abstract}

Key words: heart; ECM (extracellular matrix); growth factors; angiogenesis; vasculogenesis

\section{Introduction}

$\mathbf{T}$ HE ONLY ALTERNATIVE FOR END STAGE heart failure is orthotropic heart transplantation. Nevertheless, the lack of donor confines this route as a large-scale therapy although results are excellent after heart transplantation. ${ }^{1}$ However, xenografts have the potential to mitigate the scanty supply of human donors. Primate donors are generally rejected for practical and ethical reasons, ${ }^{2-4}$ whereas swine would be suitable donors with regard to metabolic and functional characteristics. ${ }^{5-7}$ Porcine hearts can be qualified as ideal candidate for the use as xenografts in human. ${ }^{8}$

The recent era has provided the promise of extracellular matrix as natural scaffold for attachment, proliferation, and propagation of cells in tissue engineering. In the past decade, extracellular matrix from various tissues ${ }^{9-24}$ has been used for tissue engineering. Extracellular matrix (ECM) of all tissues is known to be conducive to multicellularity of the engineered tissue like dynamic reciprocity, directing cells' behavior, antimicrobial activity, ${ }^{25}$ etc. These studies prompted us to study the ECM characteristics of decellularized por- cine whole hearts as potential scaffolds for future tissue engineering with human cells.

Although some work has been initiated in this field, the landmarks still lay in the future. Most of the work has been performed using decellularization of rodent cardiac tissue, ${ }^{20}$ and some attempts have been made with decellularized (DC) porcine cardiac patches and intact cardiac tissue. ${ }^{26-29}$ However, the analysis of intact cardiac matrix is not revealed. Also, the reinforcement of an engineered cardiac patch with acellular extracellular matrix of human heart seeded by human mesenchymal progenitor cells has been reported. However, although grafted patch was able to show the blood vessels and tissue repair, the development of contracting patch and engineering of whole heart was not achieved. Recently, the decellularization of intact cardiac tissue ${ }^{30-32}$ has been carried out using enzymatic treatment; however, enzymatic treatments can lead to the damage of ECM components. ${ }^{33}$ In this report we have described a protocol that successfully resulted in thorough decellularization of porcine whole hearts, while maintaining and conserving the biological and mechanical properties of extracellular matrix without using enzymatic treatment.

\footnotetext{
${ }^{1}$ Transplantation Institute and Department of Surgery, Sahlgrenska Academy, University of Gothenburg, Gothenburg, Sweden.

${ }^{2}$ Department of Chemistry and Materials, SP Technical Research Institute of Sweden, Borås, Sweden.

${ }^{3}$ The Electron Microscopy Unit, Institute of Biomedicine, Sahlgrenska Academy, University of Gothenburg, Gothenburg, Sweden.

${ }^{4}$ Transplant Institute and Department of Cardiothoracic Surgery, Sahlgrenska University Hospital, University of Gothenburg, Gothenburg, Sweden.

Previously presented at International Society of Heart and Lung Transplantation, 33rd Annual Meeting and Scientific Sessions, Montréal, Québec, Canada, April 23-29, 2013.
} 


\section{Materials and Methods}

The local Ethics Committee approved all protocols used in the present study.

\section{Scaffold preparation: Decellularization of porcine heart tissue}

Hearts were taken from deceased healthy pigs $(n=5)$. They were canulated through the aorta and pulmonary vein and perfused with distilled water $(\mathrm{D} / \mathrm{W})$ to remove traces of all blood clots. A biopsy piece of $2 \mathrm{~cm}^{3}$ from each tissue sample was snap frozen in liquid nitrogen and stored in $-80^{\circ} \mathrm{C}$ and used at a later time point for deoxyribonucleic acid (DNA) quantification, protein estimation and immunohistochemical analysis. All hearts were washed with phosphate buffered saline (PBS) containing $1 \%$ penicillin, $1 \%$ streptomycin, and $1 \%$ amphotericin $\mathrm{B}$ and frozen in $-80^{\circ} \mathrm{C}$ in PBS. The following day hearts were thawed at room temperature (r.t.) and washed thoroughly with (D/W).

Next, the hearts were perfused via the aorta and pulmonary vein with $4 \%$ sodium deoxycholate (SDC) for short time and immersed in a sterile beaker containing $4 \%$ SDC and placed on an orbital agitator at $37^{\circ} \mathrm{C}$ for $6 \mathrm{~h}$, followed by perfusion with $1 \%$ SDC for further $6 \mathrm{~h}$ at r.t. The hearts were then perfused with $\mathrm{D} / \mathrm{W}$ for $6 \mathrm{~h}$ at r.t. Next, the organs were perfused with $1 \%$ Triton $\mathrm{X}-100$ for $12 \mathrm{~h}$ followed by agitation in $1 \%$ Triton $\mathrm{X}-100$ for $12 \mathrm{~h}$. This decellularization cycle such as treatment with $4 \%$ SDC followed by $1 \%$ Triton $\mathrm{X}-100$ followed by extensive washing with D/W was repeated a total of eight times to obtain a completely acellular scaffold. Biopsies were collected after every decellularization cycle for histological analysis and DNA quantification.

After histological confirmation, all DC hearts were perfused with $0.1 \%$ peracetic acid in sterile PBS for $3 \mathrm{~h}$ at
A

Left auricle

FIG. 1. Immunofluorescence staining of nuclear material in normal and decellularized porcine heart. (A) DAPI (4',6-diamidino-2phenylindole, dihydrochloride) staining of normal porcine cardiac tissue sections showing brightly stained blue nuclei in normal sections. (B) In decellularized sections no staining is observed, since nuclear material is absent in the acellular scaffold. Magnification, $20 \times$.

\section{Right auricle}

Left ventricle
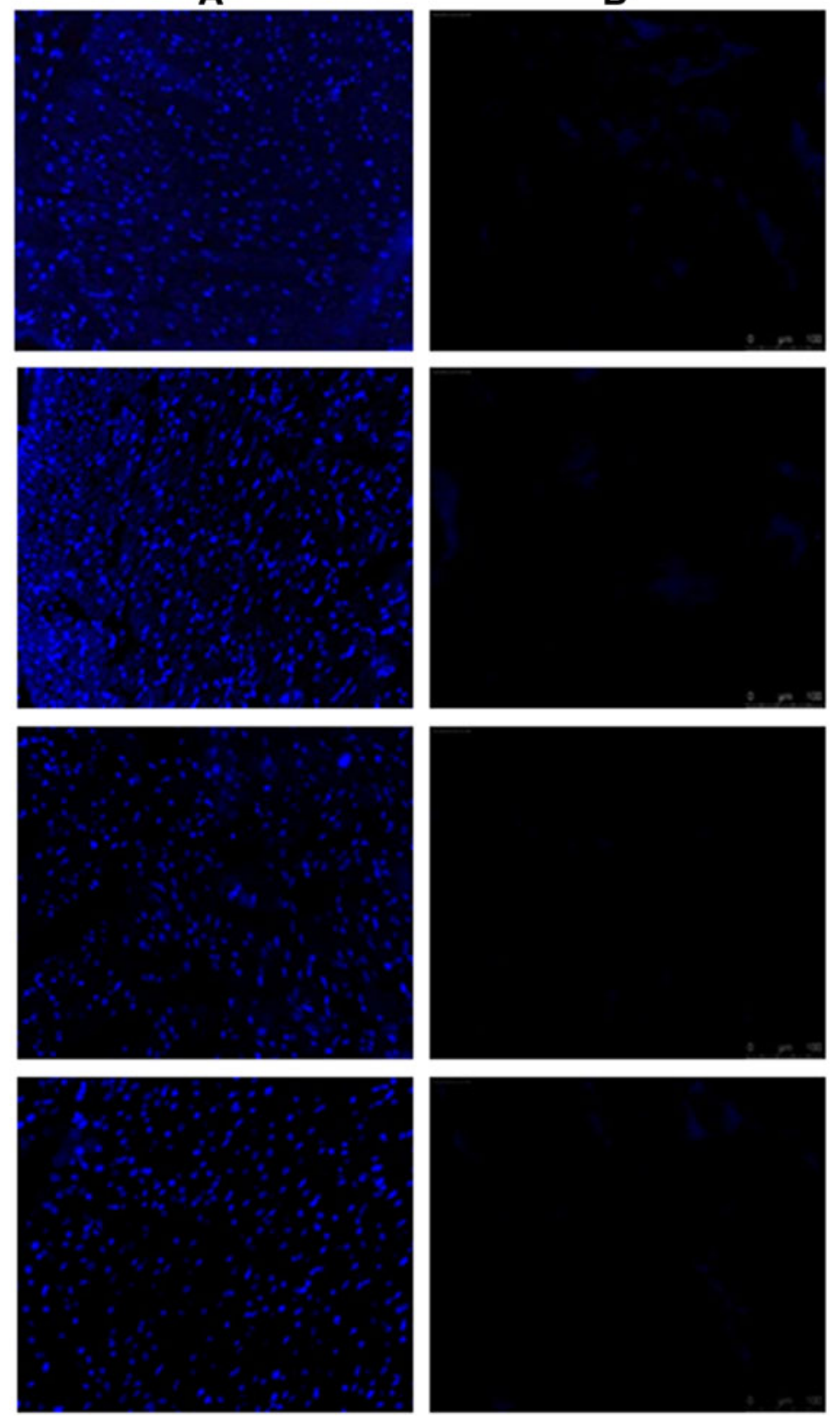
room temperature and stored in PBS containing antibiotics and antifungal solution at room temperature.

\section{Assessment of DC matrix: Confirmation of acellular state of $D C$ heart matrix}

DAPI (4',6-diamidino-2-phenylindole, dihydrochloride) staining. Normal and DC heart biopsies were embedded and frozen in optimal cutting temperature media and sectioned at 5- $\mu \mathrm{m}$ thickness. Frozen sections were fixed in acetonemethanol in a proportion of 3:7. Samples were stained with DAPI to visualize DNA present in the matrix.

DNA quantification. DNA was extracted from normal and DC heart tissue by using a commercially available kit. Biopsy was taken at every step of decellularization process to study the gradual decrease in DNA content. Digestion and extraction of tissue was carried out according to DNeasy ${ }^{\circledR}$ Blood and Tissue Handbook, included in the kit (69506, Qiagen, Sweden). Extracted DNA was quantified at $260-\mathrm{nm}$ wavelength using a nanodrop.

\section{Characterization of decellularized heart matrix}

Staining for extracellular matrix components. Normal and acellular heart biopsies were fixed in $4 \%$ formaldehyde. The paraffin sections were cut at 5- $\mu \mathrm{m}$ thickness and stained with Masson's Trichrome staining kit (Polysciences, Inc., Warrington, PA) to see the effect of surfactants on collagen arrangement in the tissue. In addition, the sections were stained for elastin, fibronectin, laminin, hyaluronic acid, and heparan sulfate (Abcam, Cambridge, United Kingdom) with the technique of immunohistochemistry.

Quantitative analysis of extracellular matrix proteins after decellularization. The amount of insoluble collagen was measured by hydroxyproline assay kit (Sigma-Aldrich, St. Louis, MO). The measurement of hydroxyproline levels gives the indirect values for insoluble collagen. The tissue samples were homogenized in distilled water and digested with concentrated hydrochloric acid at $120^{\circ} \mathrm{C}$ for $3 \mathrm{~h}$. The sample mixture was oxidized with chloramine-T/oxidation buffer mixture followed by dilution with 4-(dimethylamino) benzaldehyde reagent provided with kit. The absorbance was measured at $560 \mathrm{~nm}$.

The amount of glucosaminoglycans (GAGs) was measured using Blyscan sulfated glycosaminoglycan kit (Biocolor, Newtownabbey, United Kingdom, www.biocolor.co.uk). The tissue samples were digested with papain extraction reagent provided with kit at $65^{\circ} \mathrm{C}$. The extracted GAGs were incubated with Blyscan dye reagent to form precipitate of sulphated glycosaminoglycan-dye complex. This precipitate was further dissociated by dissociation reagent provided with kit and measured at $656 \mathrm{~nm}$ absorbance level.

The amount of elastin was measured with Fastin elastin assay kit (Biocolor). The elastin was extracted from tissue samples by digesting with oxalic acid at $100^{\circ} \mathrm{C}$ and precipitated out by using elastin-precipitating reagent provided with kit. Then the precipitate was incubated with elastin dye reagent followed by its dissociation in dye dissociation reagent, both provided with kit. Absorbance was measured at $513 \mathrm{~nm}$.

The amount of soluble collagen was measured by Sircol assay kit (Biocolor). Collagen was extracted by acid-pepsin ex- traction procedure as per the instruction manual provided with kit and precipitated out by adding acid neutralizing reagent followed by isolation and concentration reagent. Precipitate was incubated with collagen dye reagent: This complex was further recovered by addition of alkali reagent and measured at $555 \mathrm{~nm}$. The entire reagents used were provided with kit.

Analysis of residual angiogenic growth factors after decellularization. Total protein was extracted from the decellularized cardiac tissue using a commercially available kit (Millipore AB, Stockholm, Sweden, cat. no. 2140) and the protein concentration for all samples was standardized to $500 \mu \mathrm{g} / \mathrm{mL}$. The angiogenic growth factors produced by the decellularized heart were tested by Luminex technology using a commercially available kit (Millipore $\mathrm{AB}$, cat. no. HAGP1MAG-12K). The following 17 growth factors were tested: Angiopoietin-2, bone morphogenic protein (BMP9), epidermal growth factor (EGF), endoglin, endothelin-1, fibroblast growth factor (FGF)-1 (acidic FGF), FGF-2 (basic FGF), follistatin, granulocyte colony stimulating factor (G-CSF), heparin binding-EGF, hepatocyte growth factor (HGF), interleukin (IL)-8, leptin, platelet derived growth factor (PLGF), vascular endothelial growth factor A (VEGF-A), VEGF-C, and VEGF-D. Total protein from normal porcine heart was used as positive control.

\section{Electron microscopy}

Pieces from DC hearts were cut with razor blades from ventricle walls and auricles at sizes suitable for scanning and transmission electron microscopy (SEM, TEM). Specimens were fixed at $\mathrm{pH} 7.2$ in a mixture of $2 \%$ paraformaldehyde and $2.5 \%$ glutaraldehyde in $0.05 \mathrm{M}$ sodium cacodylate buffer. SEM objects were subjected to repeated treatment with osmium tetroxide ${ }^{34}$ followed by dehydration in ethanol and hexamethydisilazane, which was allowed to evaporate. The dried tissue blocks were mounted on aluminium stubs

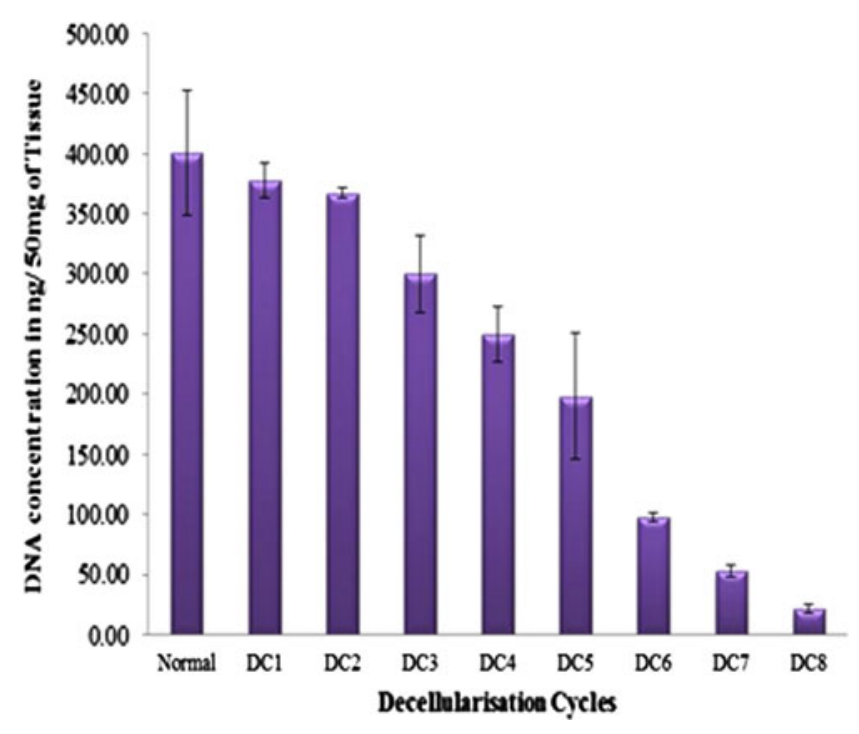

FIG. 2. DNA quantification in decellularized porcine heart tissue. Figure shows a graphical representation of quantitative analysis of nuclear material at each cycle, showing consistent decrease in double-stranded DNA through successive decellularization (DC) cycles. 
and sputter coated with palladium before examination in a Zeiss 982 Gemini scanning electron microscope.

TEM specimens were post-fixed with $1 \%$ osmium tetroxide $+1 \%$ potassium hexacyanoferrate in $0.1 \mathrm{M}$ cacodylate followed by en-bloc staining with uranyl acetate. After dehydration in ethanol and acetone specimens were infiltrated with epoxy resin and cured by heat. Ultrathin sections were obtained with a Leica UC6 ultramicrotome fitted with a diamond knife. After contrasting with lead and uranyl sections were examined in a Leo 912AB Omega transmission electron microscope (Carl Zeiss NTS, Oberkochen, Germany) equipped with a Veleta CCD camera (Olympus-SiS, Münster, Germany) for digital image recording.

\section{Biomechanical properties: Determination of tensile strength of the native and DC heart}

Two native and two DC pig hearts were tensile tested with an Instron 5566 mechanical testing system (Instron, Norwood, MA). The preload was $0.01 \mathrm{~N}$ and the test speed used was $5 \mathrm{~mm} / \mathrm{min}$. The accuracy of the tensile tester was $0.5 \%$ in force and $0.5 \%$ in elongation, based on calibrations performed regularly according to International Organization for Standardization (ISO) 7500-1:2004 and ISO 9513:1999.

Samples were taken from four different parts of the heart, left ventricle, right ventricle, left auricle, and right auricle. The ventricles were prepared into $3-\mathrm{mm}$ thin sections using a rotating blade, making clean sagittal cuts. The widths and thicknesses of the sections were measured with a vernier calliper (Mitutoyo, Kawasaki, Japan) and the samples were placed with a 5-mm gap between two sinus curve shaped jaw grips. Twelve native left ventricle segments and seven DC left ventricle segments were stretched until they break. For the right ventricle, twelve native and eight DC segments were tested. The maximum force and the vertical elongation at the maximum force were registered. Stress, strain, and stiffness were calculated.

The auricles had an inhomogeneous inner surface consisting of trabeculae. The largest diameter branch was isolated using a scalpel as well as an outer segment that appeared homogeneous.

\section{Statistics}

The data are expressed as mean \pm standard error. Statistical significance was determined by paired $t$-test for extracellular
FIG. 3. Histological analysis of normal and decellularized porcine heart tissue. (A) Masson's Trichrome staining reveals bluecolored collagen bundles, dark pink staining of cell cytoplasm, and black cell nuclei in the various parts of normal porcine heart tissue sections. (B) In decellularized tissue, the cytoplasm and muscle bands are stained pale pink and there is absence of black nuclei; however, collagen is still present, as indicated by the blue staining. Magnification, $20 \times$.
A

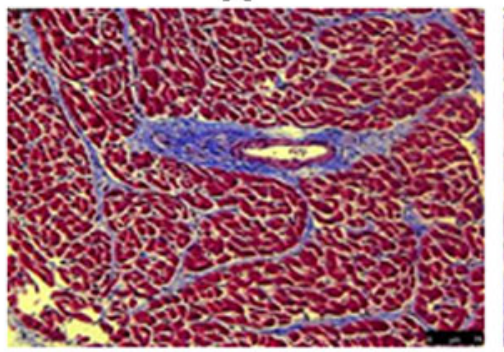

Left auricle

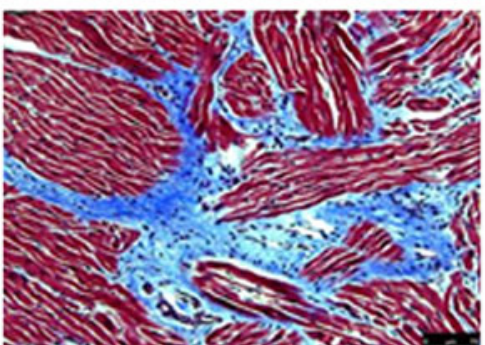

Right ventricle
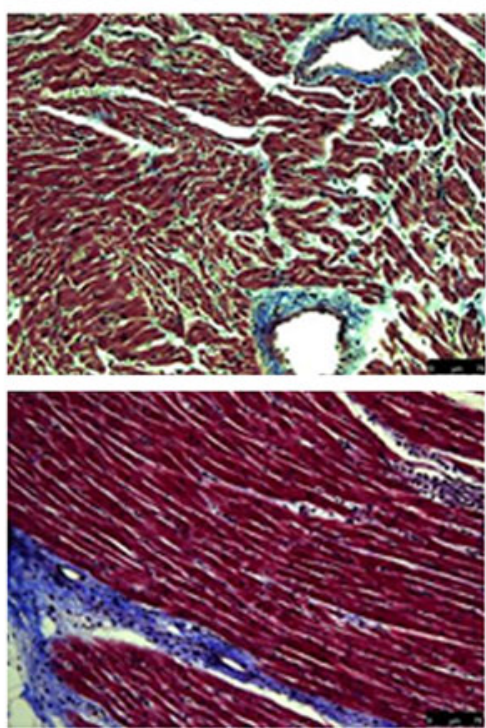

B
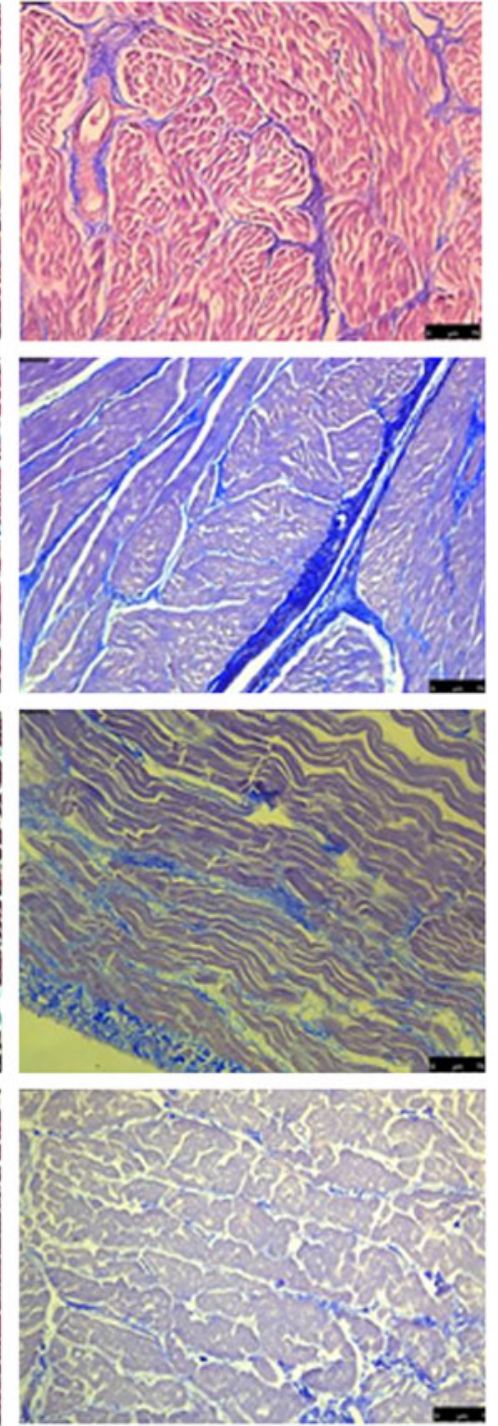
matrix components. Conducting a Grubbs test identified outliers for biomechanical properties and Mann-Whitney U tests were performed to compare it in native and DC parts of the heart. Difference ( $p$ value) of $<0.05$ was considered to be a significant difference.

\section{Results}

\section{Confirmation of acellularity}

Removal of nuclear material was confirmed by using DAPI staining performed on DC tissue. As seen in Fig. 1, no evidence of cell nuclei or residue of nuclear material could be detected in decellularized left, right auricle and left, right ventricle when compared with normal samples. Further DNA quantification showed consistent decrease in DNA concentration through successive cycles of decellularization (Fig. 2).

\section{Staining for ECM components}

Masson's trichrome staining for collagen (Fig. 3) and immunohistochemical staining for elastin (Fig. 4), fibronectin
(Fig. 5), heparan sulfate (Fig. 6) and hyluronic acid (Fig. 7) in DC hearts indicated that the arrangement of ECM components was not distorted after the decellularization process.

\section{Quantification for ECM components}

The quantification study revealed that the amount of hydroxyproline, collagen, elastin, and GAGs was not significantly altered during decellularization process in both auricles and ventricles. However, in left ventricle, the amount of GAGs was found to be significantly affected in the whole process (Tables 1 and 2).

\section{Growth factors produced by cardiac tissue}

Using the technology of Luminex we found several residual growth factors present in the decellularized cardiac tissue (Fig. 8). The decellularization process did not significantly affect the amount of leptin, FGF-1, IL-8, VEGF-C, and VEGF-A in both auricles and ventricles. Interestingly the amount of endothelin-1 was not altered in ventricles but was affected in auricles. In general, the rest of the tested
A

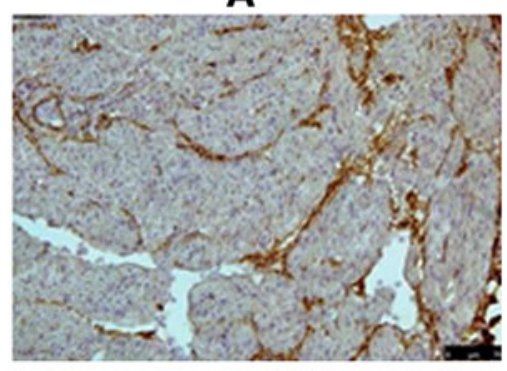

Right auricle

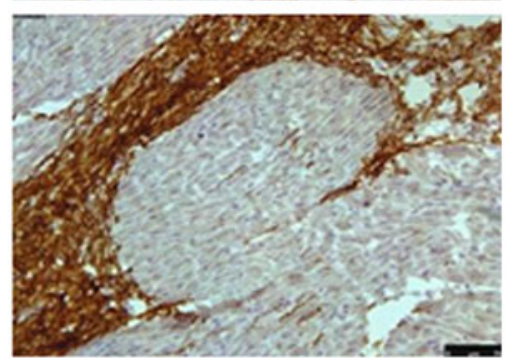

Left auricle

Right ventricle

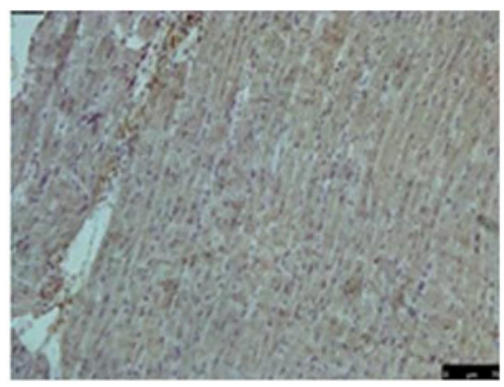

Left ventricle

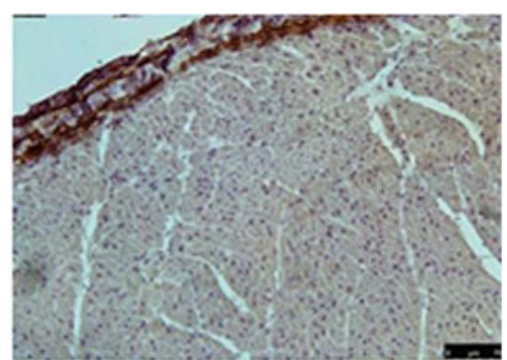

B
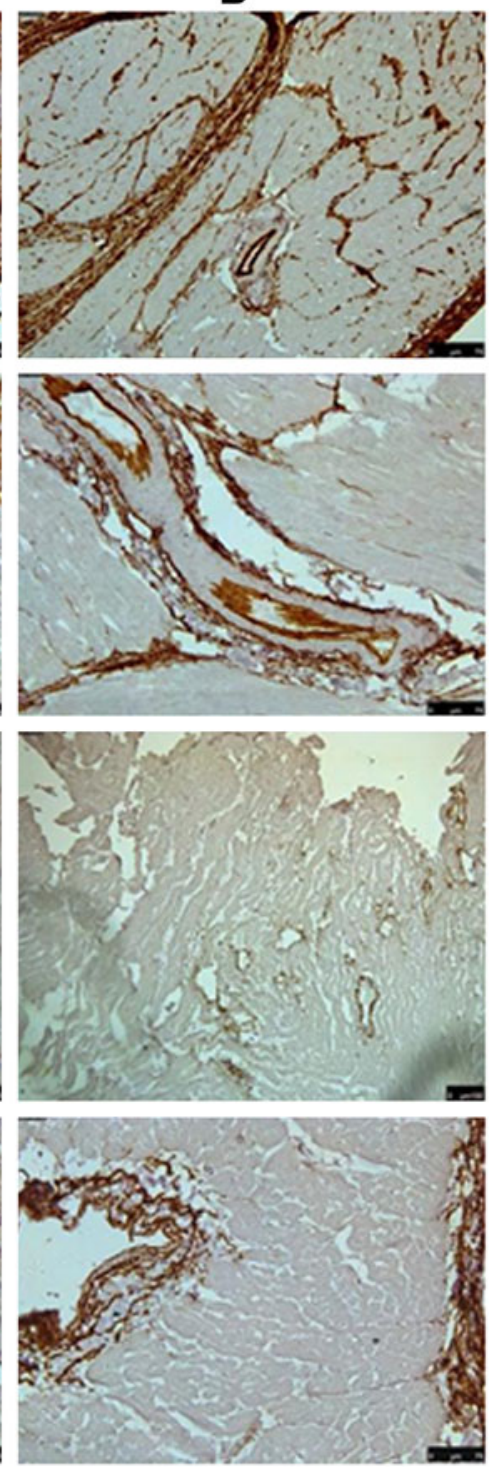

FIG. 4. Immunohistochemical stainings of normal and decellularized porcine heart tissue. (A) Tissue sections from various parts of normal porcine heart tissue showing positive brown staining for elastin when stained with anti-elastin antibodies. (B) The positive brown staining for elastin was also present in the decellularized tissue, indicating that the process did not have a major effect on the extracellular matrix (ECM). Magnification, $20 \times$. 
FIG. 5. Immunohistochemical stainings of normal and decellularized porcine heart tissue. (A) Tissue sections from various parts of normal porcine heart tissue showing positive brown staining for fibronectin especially around the blood vessels when stained with antifibronectin antibodies. (B) The positive brown staining for fibronectin around the blood vessels was also present in the decellularized tissue, indicating that the process did not have a major effect on the ECM. Magnification $20 \times$.
A

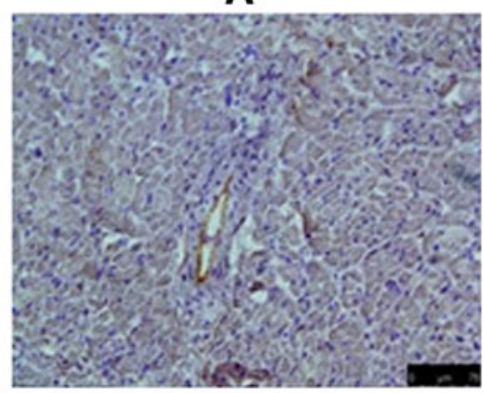

Right auricle

Right ventricle
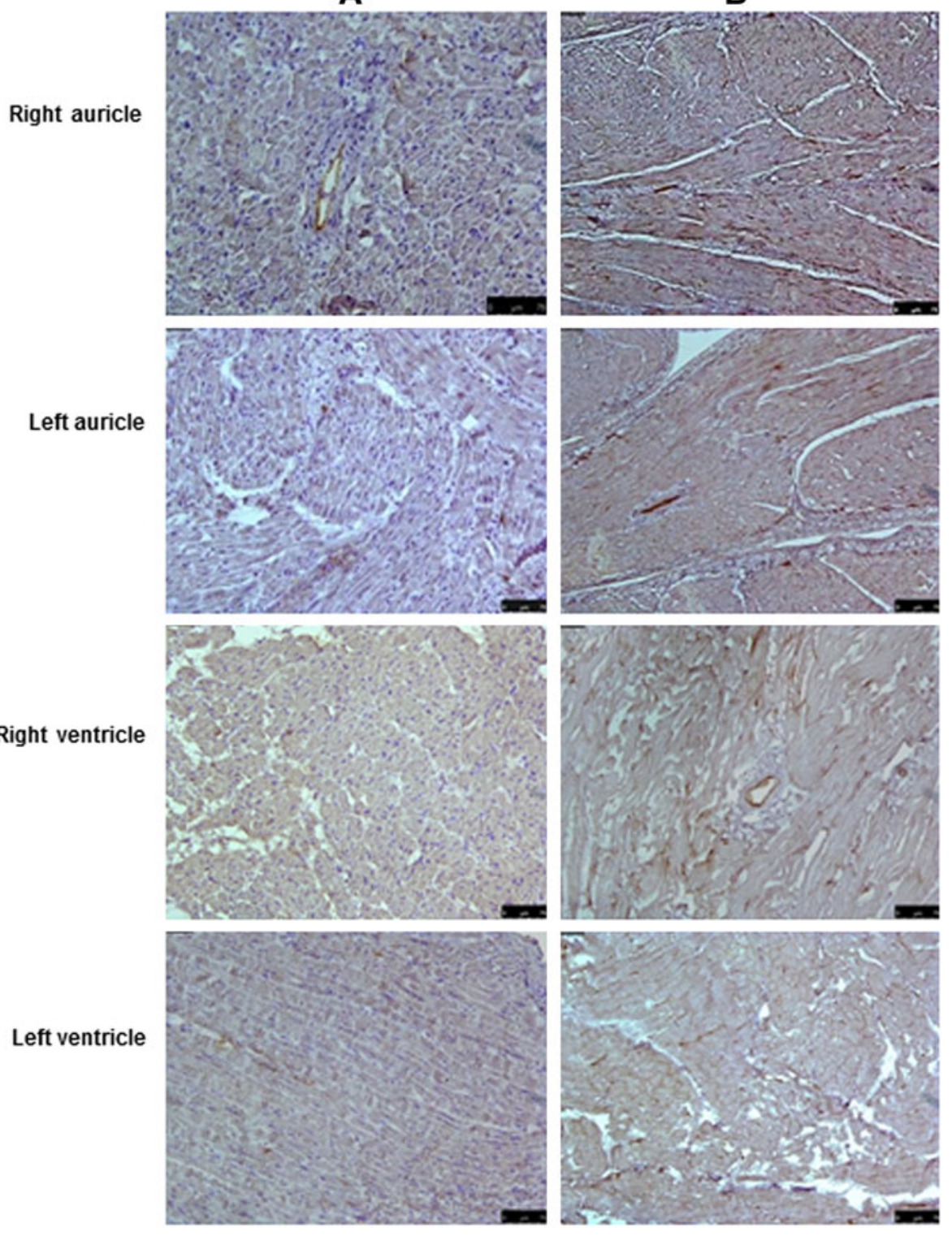

growth factors were decreased but it was not completely eradicated in the decellularization process.

\section{Electron microscopic analysis of the decellularized heart}

SEM analysis revealed that natural surfaces of the organ (endocardium, pericardium, veins, and arteries) were devoid of cells, leaving areas formed of very dense meshworks of delicate filaments, reasonably representing denuded basal laminae (Fig. 9A a, b). The status of the bundles of cardiomyocytes, their microvascular supply, and intervening strands of matrix components, was more difficult to evaluate in the SEM after decellularization. At some sites, the excised tissue blocks seemed to present profiles of muscle cells at low magnification that at high magnification were composed of closely packed filament bundles. We did not observe any empty spaces in a pattern that would be the result if cardiomyocytes had simply been removed as whole entities (Fig. 9A c, d).

The TEM visualization of the tissue gave an unambiguous explanation to the SEM findings: the contractile cross-striated apparatus of myocytes was largely retained in an undisturbed order in the tissue (Fig. 9B a, b). Likewise, dense plaques and their intermediate filament insertions of desmosomes in intercalated discs were readily identified. On the other hand, there were no traces encountered of those elements that are formed by cellular membranes (i.e., sarcolemma, intracellular tubules, mitochondria, nuclei), nor did we observe remnants of cytoplasmic inclusions such as glycogen deposits or lipid droplets. Further, it was not possible to identify connective tissue cells or components of the microvasculature (Fig. 9B c).

\section{Biomechanical analysis of the decellularized hearts}

The heart wall stretched to about double its original length while the measured stress remained low (approximately below $50 \mathrm{~Pa}$ ). At that point, the elastic components of the wall were stretched and an increase in measured force was seen, the increase continued until failure. The samples broke in segments, first an arrangement of fibers was broken and other smaller breaks occurred after until there where only 
A
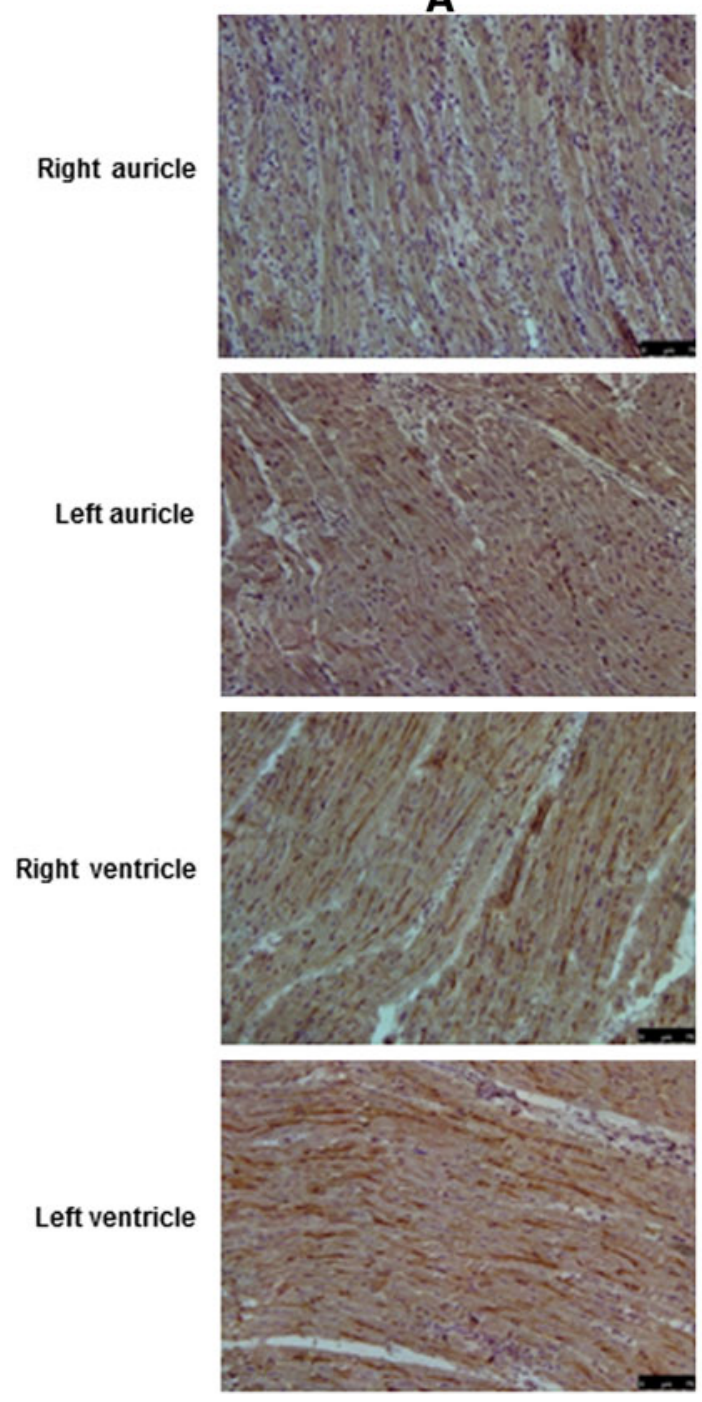

B
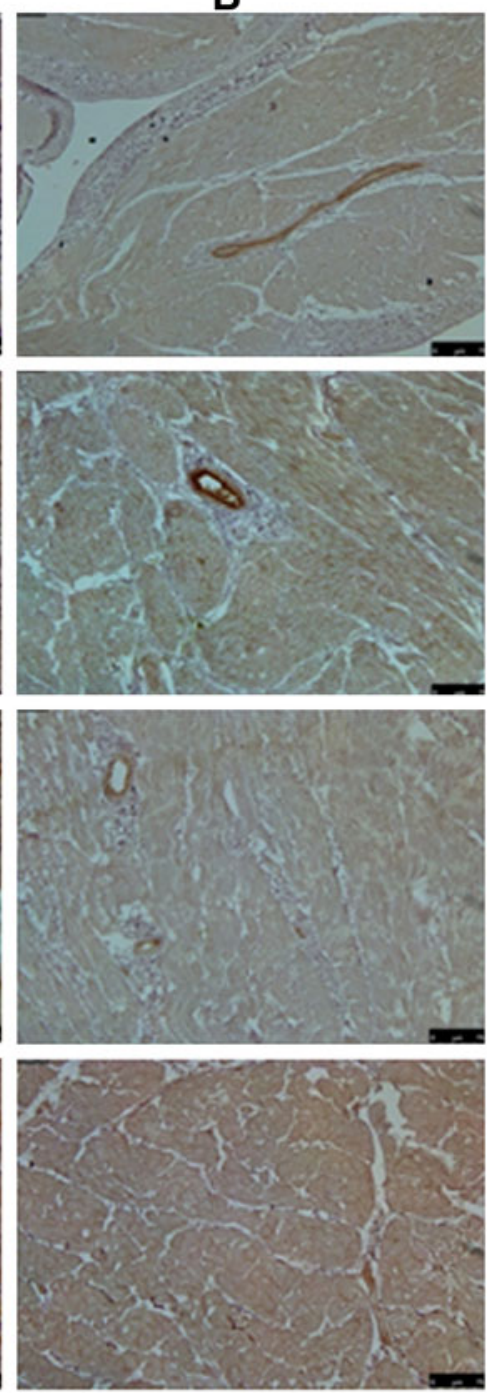

FIG. 6. Immunohistochemical stainings of normal and decellularized porcine heart tissue. (A) Tissue sections from various parts of normal porcine heart tissue showing positive brown staining for heparan sulphate evenly throughout the tissue when stained with anti-heparan sulphate antibodies. (B) The positive brown staining for heparan sulphate was also present in the decellularized tissue, albeit slightly lower. Magnification $20 \times$. a few fibers left. This is clearly seen in the DC-RV graph, where all small breaks correspond to a peak after the initial break. Although there were some differences in deformation behavior between samples, a majority of the samples behaved in this way (Fig. 10A).

The right ventricle showed a higher elastic modulus than the left ventricle. The decellularization process significantly increased the stiffness on the left ventricle, but not for the right ventricle (Fig. 10B).

The stresses measured on native hearts were higher on the right ventricle than on the left ventricle. The measured stresses after decellularization were significantly higher than the native heart for both the left and right ventricle (Fig. 10C). The strain at maximum stress was not significantly different between the tested samples (Fig. 10D).

\section{Discussion}

The availability of human heart donors is limited due to worldwide organ scarcity. Alternative biological scaffolds such as use of xenogeneic tissue need to be tested for tissue engineering with human cells. Cardiac patches have been decellularized and studied to better understand the structural and biomechanical properties of the porcine myocardial ECM for tissue-engineering. ${ }^{25,35-39}$ However, cardiac xenografts patches are not a realistic alternative to human donor hearts treating patients with heart failure. Therefore, the purpose of our study was to explore if porcine whole heart decellularization has the potential as acellular porcine cardiac scaffold and possible template for cardiac tissue engineering. One possible concept in cardiac tissue engineering is to use decellularized xenogeneic matrices with allogeneic fetal cardiac cells or if possible, autologous human cell reseeding. The decellularization process is crucial, as all cells need to be removed in order to prevent any adverse immune response post-transplantation. Reciprocally, the decellularization process must also preserve the structural components of the ECM relatively unaltered to provide a biomechanically sustainable scaffold and promote efficient reseeding. Xenogeneic ECM has been shown to be an effective scaffold for the repair and reconstitution of several tissues. ${ }^{40}$

In this study, we report the feasibility of extracting an acellular matrix scaffold with retention of important biological features by decellularizing the whole porcine heart. Initial freezing and thawing can help for mechanical disruption of the cells. We observed near complete removal of cellular 
FIG. 7. Immunohistochemical stainings of normal and decellularized porcine heart tissue. (A) Tissue sections from various parts of normal porcine heart tissue showing positive brown staining for hyaluronic acid when stained with antihyaluronic acid antibodies. (B) The positive brown staining for hyaluronic acid was also present in the decellularized tissue, albeit slightly lower. Magnification $20 \times$.
A

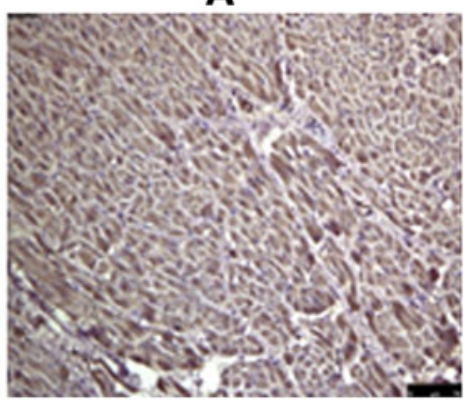

Right auricle

Left auricle

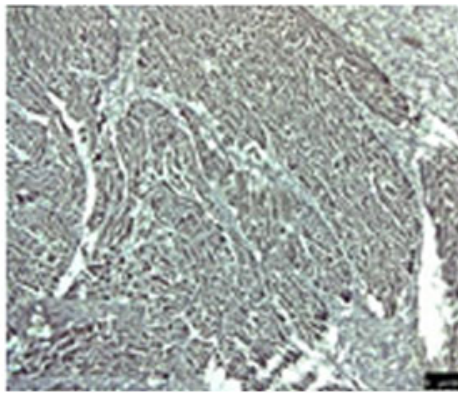

Right ventricle

Left ventricle
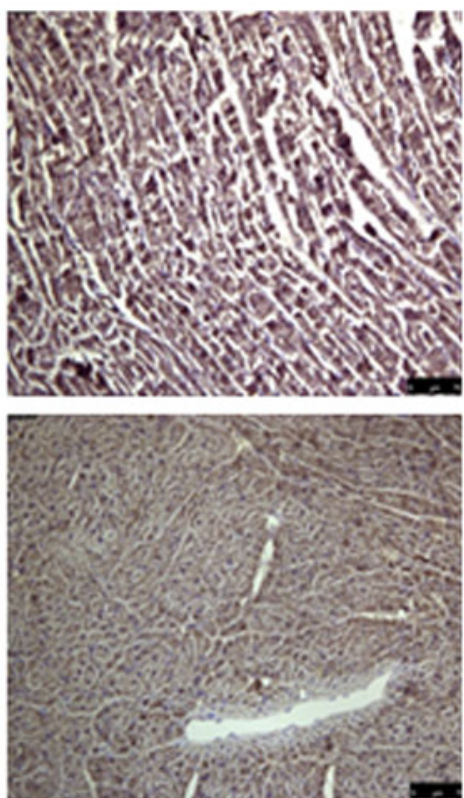

B
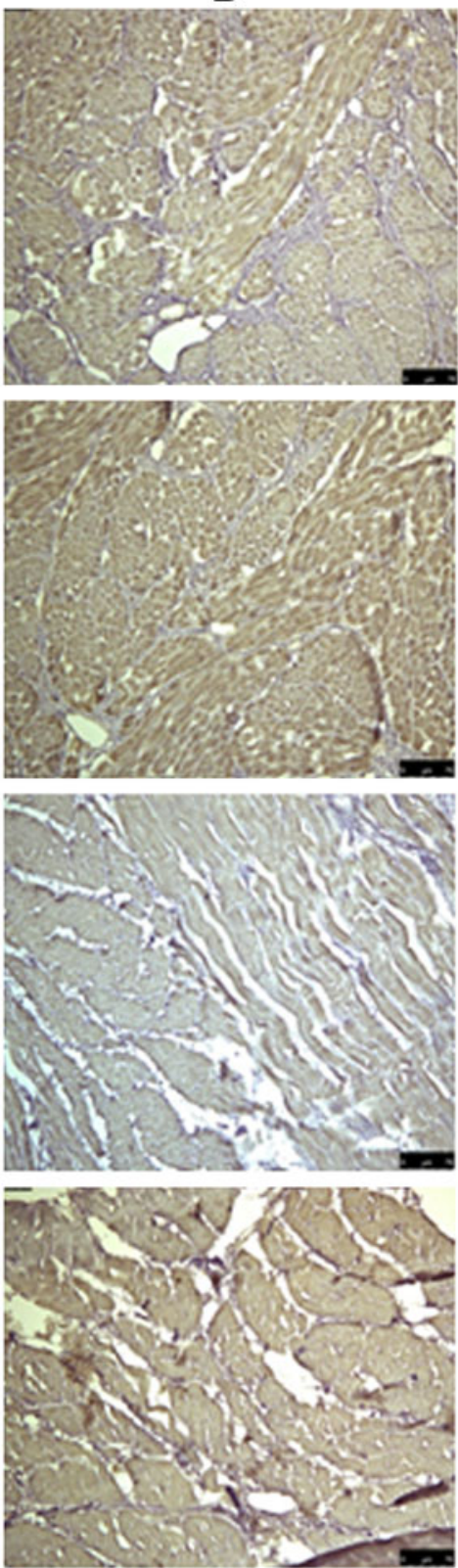

Table 1. Amount of Extracellular Matrix Proteins in Normal and Decellularized Porcine Heart

\begin{tabular}{|c|c|c|c|c|c|c|c|c|}
\hline & \multicolumn{2}{|c|}{ Right auricle } & \multicolumn{2}{|c|}{ Left auricle } & \multicolumn{2}{|c|}{ Right ventricle } & \multicolumn{2}{|c|}{ Left ventricle } \\
\hline & Normal & $D C$ & Normal & $D C$ & Normal & $D C$ & Normal & $D C$ \\
\hline $\begin{array}{l}\text { Hydroxyproline in } \\
\mu \mathrm{g} / \mathrm{mg} \text { of tissue }\end{array}$ & $13.85 \pm 2.01$ & $12.85 \pm 2.1$ & $15.98 \pm 3.23$ & $15.51 \pm 1.67$ & $8.95 \pm 1.56$ & $7.79 \pm 0.13$ & $4.86 \pm 0.86$ & $5.91 \pm 1.88$ \\
\hline $\begin{array}{l}\text { Soluble collagen in } \\
\mu \mathrm{g} / \mathrm{mg} \text { of tissue }\end{array}$ & $3.65 \pm 0.02$ & $4.77 \pm 2.64$ & $12.79 \pm 4.28$ & $4.37 \pm 2.77$ & $19.25 \pm 7.69$ & $9.51 \pm 2.35$ & $14.01 \pm 9.01$ & $18.69 \pm 10.93$ \\
\hline $\begin{array}{l}\text { Elastin in } \mu \mathrm{g} / \mathrm{mg} \\
\quad \text { of tissue }\end{array}$ & $21.57 \pm 2.71$ & $36.58 \pm 6.37$ & $28.53 \pm 4.10$ & $24.69 \pm 5.05$ & $31.68 \pm 4.28$ & $27.04 \pm 6.89$ & $36.53 \pm 4.70$ & $22.80 \pm 0.14$ \\
\hline $\begin{array}{l}\text { GAGs in } \mu \mathrm{g} / \mathrm{mg} \\
\text { of tissue }\end{array}$ & $21.88 \pm 8.85$ & $5.75 \pm 1.03$ & $33.20 \pm 13.85$ & $10.20 \pm 2.66$ & $41.59 \pm 13.95$ & $6.73 \pm .2 .15$ & $40.58 \pm 1.36$ & $7.25 \pm 1.17$ \\
\hline
\end{tabular}

DC, decellularized; GAGs, glucosaminoglycans. 
Table 2. Statistical Difference ( $P$ Values) in Amount of Extracellular Matrix Components in Normal and Decellularized Heart

\begin{tabular}{lcclc}
\hline & $\begin{array}{c}\text { Right } \\
\text { auricle }\end{array}$ & $\begin{array}{c}\text { Left } \\
\text { auricle }\end{array}$ & $\begin{array}{c}\text { Right } \\
\text { ventricle }\end{array}$ & $\begin{array}{c}\text { Left } \\
\text { ventricle }\end{array}$ \\
\hline Hydroxyproline & 0.758 & 0.927 & 0.540 & 0.686 \\
Soluble collagen & 0.712 & 0.073 & 0.291 & 0.821 \\
Elastin & 0.124 & 0.299 & 0.714 & 0.102 \\
GAGs & 0.219 & 0.111 & 0.219 & 0.001 \\
\hline
\end{tabular}

and nuclear components by the use of SDC and Triton X-100 in eight cycles of decellularization as judged by our results of nuclear staining with DAPI and DNA quantification study. However, the number of cycles required for decellularization can vary from six to eight. Our results suggest that perfusion and agitation of whole porcine hearts with SDC and Triton $\mathrm{X}-100$ produces a well-preserved xenogeneic three-dimensional acellular neoscaffold and may represent an important and potential scaffold for recellularization with human cardiac cells.

An important finding is that the highly organized components of cytoskeletal elements (i.e., the contractile apparatus and the desmosomal parts of intercalated discs) were largely unaffected by detergent treatment. Interestingly, the molecular order of overlapping myofilaments, as reflected by the banding pattern, was identical to the situation of freshly fixed live tissue although there was a complete disintegration of membranous structures of the cardiomyocytes. Accordingly, further elaboration of the decellularization procedure must be done if complete removal of muscle cell contents is defined as a necessary prerequisite for a useful scaffold.

In our study, the expression of collagen and elastin was observed even after the decellularization treatment. We also found abundant expression of the adhesive protein fibronectin, which is known to act as bridge between the cells and ECM. Furthermore, strong staining for heparan sulphate one of the proteoglycan present in the GAGs and hyaluronic acid a nonproteoglycan of GAGs was observed in the DC tissue. Heparan sulphate is a binding site for various growth factors ${ }^{41}$ and thus helps in various biological processes whereas hyaluronic acid provides the turgor force to the tissue under stressful conditions. In addition, uniaxial mechanical testing showed a stiffer mechanical response of the acellular myocardial scaffolds. Thus, our immunohistochemical staining's suggested stable extracellular matrix fiber morphology, and quantitative analysis of collagen and elastin suggest stable structural components within the fibers themselves. Thus,
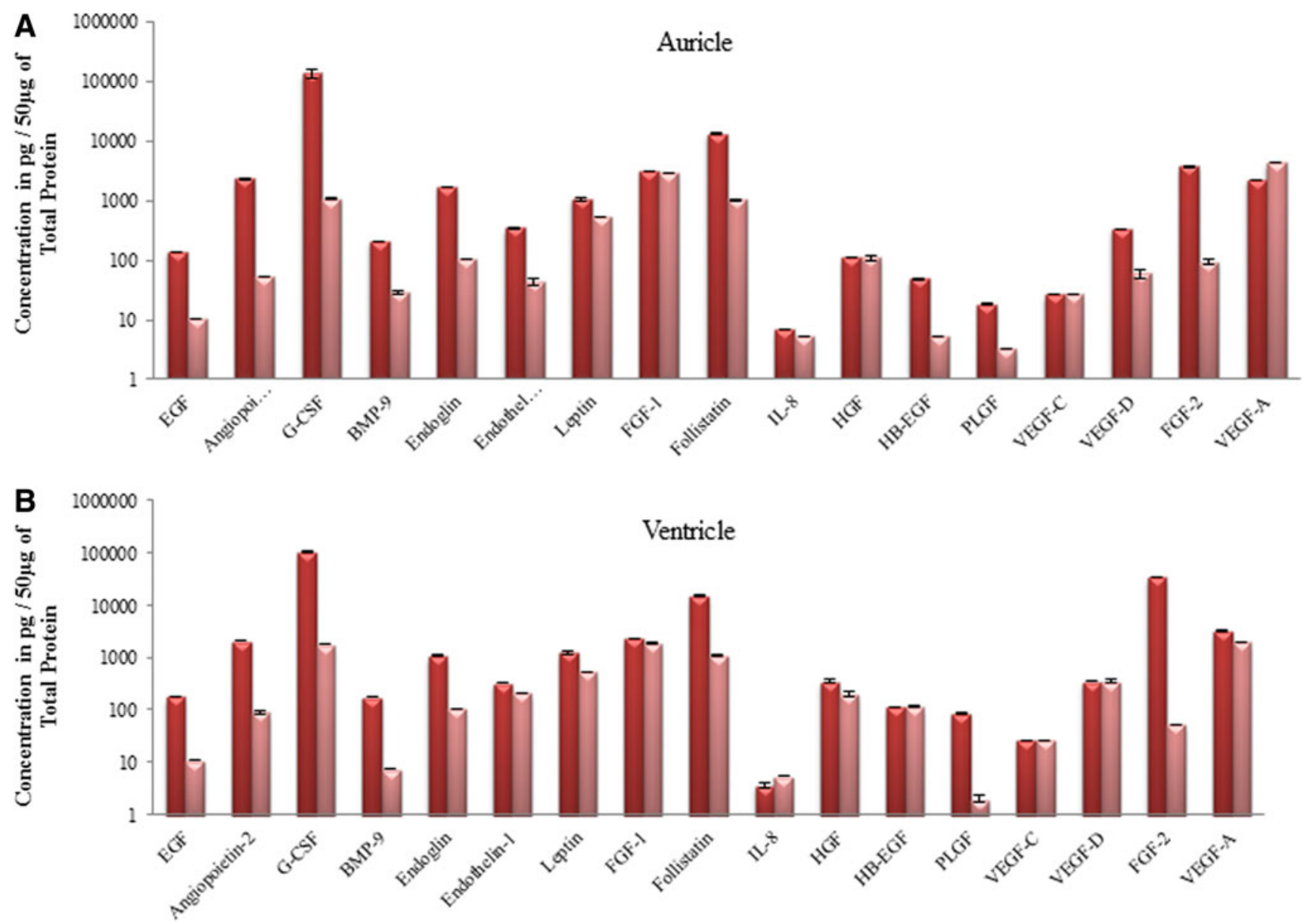

FIG. 8. Detection of growth factors in normal and decellularized porcine heart tissue. (A, B) Bar diagrams showing amount of growth factors in auricles and ventricles of normal (dark pink) and decellularized (light pink) porcine heart tissues using Luminex technology. As seen, all of the growth factors were still present, albeit at lower concentrations even after the process of decellularization. 
A
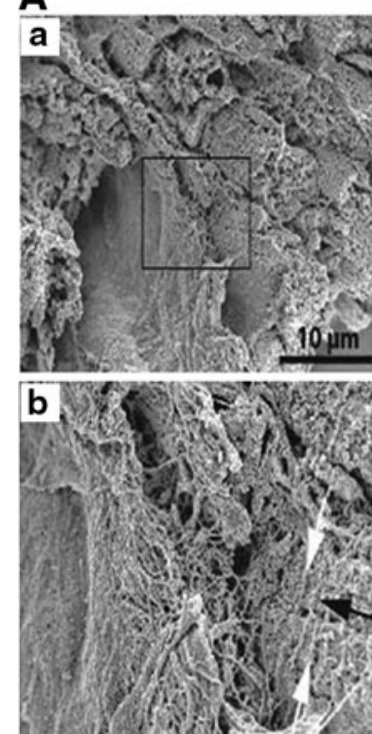
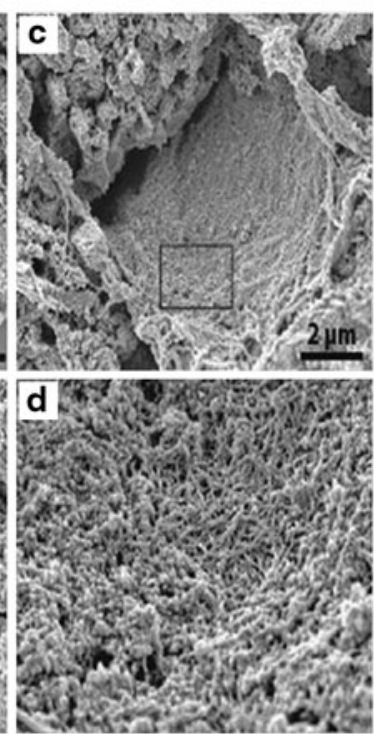

B

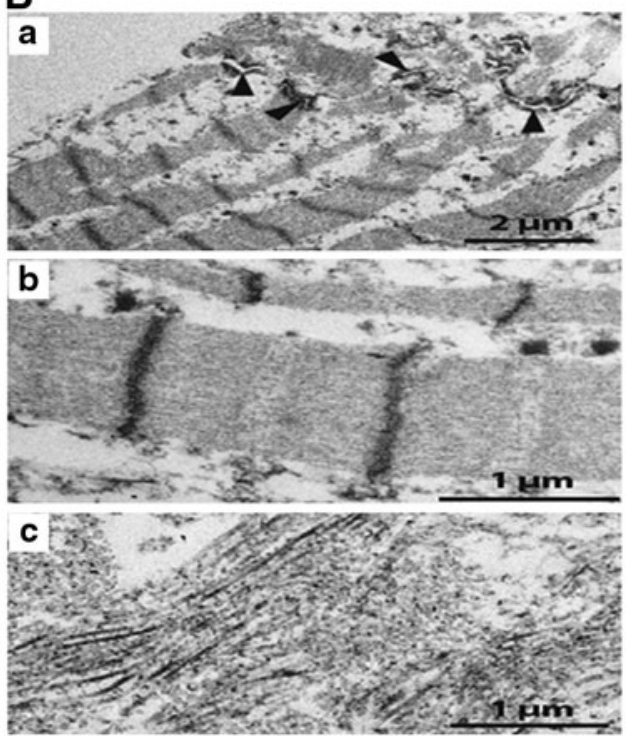

FIG. 9. Mount of scanning electron micrographs from decellularized myocardium, (a) and (c) at low power, (b) and (d) are the magnified rectangles. (A) Micrograph (a) depicts a region where a probable former vessel is located in a center-left position flanked by a number of parallel, transversely cut trabecles to the right. The latter display a cross-striated surface. In (b) a rich network of matrix filaments are resolved inside and outside the assumed vessel together with cross-striating ridges (white arrows) perpendicular to the longitudinal axis (black arrow) of the trabecular profiles. Panel (c) shows a probable vessel ghost, the luminal surface of which is detailed in (d). A very tightly woven network of fine matrix filaments is revealed. (B) TEM images of decellularized myocardium. In (a) the retained cross-striated myofilament bundles are obvious. The remnants of an intercalated disc are visible; its desmosomal components are indicated by arrowheads. At higher resolution (b) the undisturbed banding of the contractile apparatus is obvious and individual myosin and actin filaments are discernible. There are no remnants of membrane-bound cell organelles. Image (c) represents a tissue region devoid of cardiomyocyte ghosts exhibiting whorls of collagen fibers in various directions.
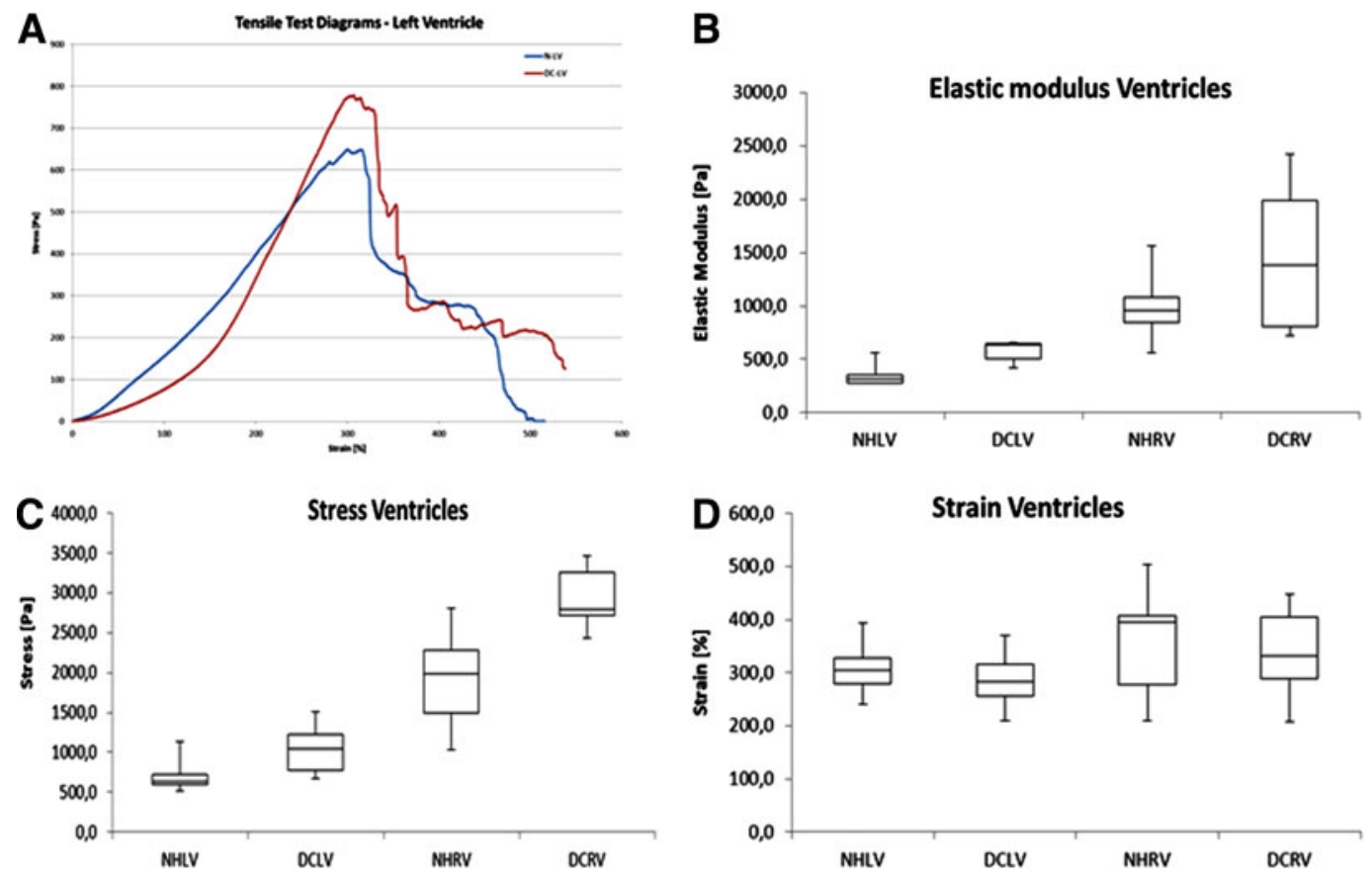

FIG. 10. (A) Representative stress/strain diagrams for native and decellularized left ventricle segments. (B) The elastic modulus gives a measurement of stiffness of the materials. The right ventricle showed a higher elastic modulus than the left ventricle. There was a significant difference between the NHLV and DCLV samples, but not between the NHRV and DCRV samples. (C, D) Box and whisker diagram of measured stress (C) and strain (D) from tensile tests. The LVDC heart segments could withstand significantly higher stress before breaking compared with the corresponding native ventricle, while the RV samples showed no significant difference. No significant differences in strain were found between the native and decellularized samples. $\mathrm{NH}$, native heart; LV, left ventricle; DC, decellularized heart; RV, right ventricle. 
these results suggest the possibility of ECM having enough structural integrity to provide strength for multicellularity of the tissue.

To further evaluate our ECM for its ability to support recellularization, we tested for the presence of growth factors after the decellularization process. In our Luminex study, we found the presence of various growth factors involved in (a) angiogenesis, such as VEGF-A, VEGF-C, VEGF-D ${ }^{43}$ FGF1, and low levels of FGF-2 in ventricles; (b) maintenance of cardiac homeostasis and remodelling, such as leptin, endothelin, and low levels of follistatin and angiotensin; and (c) mitogenic cardiokines such as platelet derived growth factor, HGF, endoglin, and BMP-9. In addition, we also found the presence of G-CSF and IL-8, which are known to induce proliferation, survival, differentiation, and recruitment of cells in response to inflammation. Our results suggest that these scaffolds can act as an inductive template for functional tissue and organ reconstruction after recellularization with autologous stem cells or differentiated cells. Various cell types, such as stem cells (bone marrow stem cells, umbilical stem cells, embryonic stem cells), multipotent adult progenitor cells, fetal cardiomyocytes, smooth muscle cells, and dermal fibroblasts, can be investigated as cell sources for recellularization. ${ }^{42-47}$ In fact recently, Wong et al. ${ }^{38,39}$ assessed the potential of a decellularized porcine myocardium patch as a tissue engineered template and demonstrated that the native three-dimensional cardiomyocytes, lacunae, and ECM networks were preserved and the acellular porcine myocardial scaffold showed potential in supporting cell reseeding, cell differentiation, and endothelialization of vasculature channels.

There are a number of limitations associated with our study. It is important to point out that the exact functional significance of the various amounts of ECM proteins and growth factors levels detected in this study is currently unknown. What quantities of ECM proteins or growth factors are required for successful recellularization is also not known. Another shortcoming of our study is the question, whether the porcine matrix carries potential immunogenic reactions and infectious risks through the transmission of porcine endogenous retrovirus $^{48}$ or $\alpha$-Gal epitopes. For this reason, further studies are required to confirm or exclude these obstacles.

\section{Conclusion}

The DC porcine whole heart retains the natural architecture of myocardial extracellular matrix, which may have the potential to promote stem cell differentiation, cardiac regeneration, and angiogenesis. Furthermore, our model serves as a useful and simple tool for different studies that allows production of three-dimensional myocardial neoscaffolds. Such scaffolds may one day be suitable for clinical applications.

\section{Acknowledgments}

This study was financed by the Swedish Heart and Lung foundation and the Swedish Government LUA ALF grants, The IngaBritt, and Arne Lundberg foundation and the Swedish Medical council K2013-65X-22347-01-3 to SSH.

\section{Author Disclosure Statement}

No competing financial interests exist.

\section{References}

1. Dellgren G, Geiran O, Lemstrom K, et al. Three decades of heart transplantation in Scandinavia: long-term follow-up. Eur J Heart Fail. 2013;15:308-315.

2. Have a pig's heart? Lancet. 1997;349:219.

3. Cooper DK, Keogh AM, Brink J, et al. Report of the Xenotransplantation Advisory Committee of the International Society for Heart and Lung Transplantation: the present status of xenotransplantation and its potential role in the treatment of end-stage cardiac and pulmonary diseases. J Heart Lung Transplant. 2000;19:1125-1165.

4. Dickson D. Britain may set up genetics advisory body. Nature. 1996;380:6.

5. Kirkman RL. Of Swine and Men - Organ Physiology in Different Species. Int Congr Ser. 1989;880:125-132.

6. Schulze J. The germ-free animal in biomedical research. In: Laboratory animal handbooks 9. Von Herausgegeben M, Coates E, Gustafsson BE, eds. 442 Seiten, Laboratory animals LTD, London, Großbritannien, 1984. Food/Nahrung. 1985;29:628.

7. Tumbleson ME. Swine in biomedical research. Plenum Press: New York, NY, 1986.

8. Siepe M, Martin J, Sarai K, et al. Anatomical study on the surgical technique used for xenotransplantation: Porcine hearts into humans. J Surg Res. 2007;143:211-215.

9. Badylak SF, Lantz GC, Coffey A, et al. Small intestinal submucosa as a large diameter vascular graft in the dog. J Surg Res. 1989;47:74-80.

10. Badylak SF, Tullius R, Kokini K, et al. The use of xenogeneic small-intestinal submucosa as a biomaterial for achilles-tendon repair in a dog-model. J Biomed Mater Res. 1995;29:977-985.

11. Booth C, Korossis SA, Wilcox HE, et al. Tissue engineering of cardiac valve prostheses I: development and histological characterization of an acellular porcine scaffold. J Heart Valve Dis. 2002;11:457-462.

12. Chen F, Yoo JJ, Atala A. Acellular collagen matrix as a possible "off the shelf" biomaterial for urethral repair. Urology. 1999;54:407-410.

13. Chen RN, Ho HO, Tsai YT, et al. Process development of an acellular dermal matrix (ADM) for biomedical applications. Biomaterials. 2004;25:2679-86.

14. Conklin BS, Richter ER, Kreutziger KL, et al. Development and evaluation of a novel decellularized vascular xenograft. Med Eng Phys. 2002;24:173-183.

15. Cortiella J, Niles J, Cantu A, et al. Influence of acellular natural lung matrix on murine embryonic stem cell differentiation and tissue formation. Tissue Eng Pt A. 2010;16:2565-2580.

16. Dahl SLM, Koh J, Prabhakar V, et al. Decellularized native and engineered arterial scaffolds for transplantation. Cell Transplant. 2003;12:659-666.

17. Grauss RW, Hazekamp MG, Oppenhuizen F, et al. Histological evaluation of decellularised porcine aortic valves: matrix changes due to different decellularisation methods. Eur J Cardiothoracic Surg. 2005;27:566-571.

18. Kasimir MT, Rieder E, Seebacher G, et al. Comparison of different decellularization procedures of porcine heart valves. Int J Artif Organs. 2003;26:421-427.

19. Kropp BP. Experimental assessment of small-intestinal submucosa as a bladder wall substitute - reply. Urology. 1995;46:396-400.

20. Ott HC, Matthiesen TS, Goh SK, et al. Perfusion-decellularized matrix: using nature's platform to engineer a bioartificial heart. Nat Med. 2008;14:213-221. 
21. Petersen TH, Calle EA, Zhao LP, et al. Tissue-engineered lungs for in vivo implantation. Science. 2010;329:538-541.

22. Schenke-Layland K, Vasilevski O, Opitz F, et al. Impact of decellularization of xenogeneic tissue on extracellular matrix integrity for tissue engineering of heart valves. J Struct Biol. 2003;143:201-208.

23. Taylor DA. From stem cells and cadaveric matrix to engineered organs. Curr Opin Biotech. 2009;20:598-605.

24. Uygun BE, Soto-Gutierrez A, Yagi H, et al. Organ reengineering through development of a transplantable recellularized liver graft using decellularized liver matrix. Nat Med. 2010;16:814-820.

25. Brennan EP, Reing J, Chew D, et al. Antibacterial activity within degradation products of biological scaffolds composed of extracellular matrix. Tissue Eng. 2006;12:2949-2955.

26. Eitan Y, Sarig U, Dahan N, et al. Acellular cardiac extracellular matrix as a scaffold for tissue engineering: in vitro cell support, remodeling, and biocompatibility. Tissue Eng Part C Methods. 2010;16:671-683.

27. Sarig U, Au-Yeung GCT, Wang Y, et al. Thick acellular heart extracellular matrix with inherent vasculature: a potential platform for myocardial tissue regeneration. Tissue Eng Part A. 2012;18:2125-2137.

28. Singelyn JM, Christman KL. Modulation of material properties of a decellularized myocardial matrix scaffold. Macromol Biosci. 2011;11:731-738.

29. Wainwright JM, Czajka CA, Patel UB, et al. Preparation of cardiac extracellular matrix from an intact porcine heart. Tissue Eng Part C Methods. 2010;16:525-532.

30. Bronshtein T, Au-Yeung GC, Sarig U, et al. A mathematical model for analyzing the elasticity, viscosity, and failure of soft tissue: comparison of native and decellularized porcine cardiac extracellular matrix for tissue engineering. Tissue Eng Part C Methods. 2013;19:620-630.

31. Remlinger NT, Wearden PD, Gilbert TW. Procedure for decellularization of porcine heart by retrograde coronary perfusion. J Vis Exp. 2012; e50059.

32. Wainwright JM, Hashizume R, Fujimoto KL, et al. Right Ventricular outflow tract repair with a cardiac biologic scaffold. Cells Tissues Organs. 2012;195:159-170.

33. Akhyari P, Aubin H, Gwanmesia P, et al. The quest for an optimized protocol for whole-heart decellularization: a comparison of three popular and a novel decellularization technique and their diverse effects on crucial extracellular matrix qualities. Tissue Eng Part C Methods. 2011;17:915-926.

34. Friedman PL, Ellisman MH. Enhanced visualization of peripheral nerve and sensory receptors in the scanning electron microscope using cryofracture and osmium-thiocarbohydrazideosmium impregnation. J Neurocytol. 1981;10:111-131.

35. Badylak SF, Taylor D, Uygun K. Whole-organ tissue engineering: decellularization and recellularization of threedimensional matrix scaffolds. Annu Rev Biomed Eng. 2011;13:27-53.

36. Crapo PM, Gilbert TW, Badylak SF. An overview of tissue and whole organ decellularization processes. Biomaterials. 2011;32:3233-3243.

37. Godier-Furnemont AFG, Martens TP, Koeckert MS, et al. Composite scaffold provides a cell delivery platform for cardiovascular repair. P Natl Acad Sci U S A. 2011;108:7974-7979.

38. Wang B, Borazjani A, Tahai M, et al. Fabrication of cardiac patch with decellularized porcine myocardial scaffold and bone marrow mononuclear cells. J Biomed Mater Res A. 2010;94:1100-1110.
39. Wang B, Tedder ME, Perez CE, et al. Structural and biomechanical characterizations of porcine myocardial extracellular matrix. J M Sci Mat Med. 2012;23:1835-1847.

40. Badylak SF. The extracellular matrix as a scaffold for tissue reconstruction. Semi Cell Dev Biol. 2002;13:377-383.

41. Corda S, Samuel JL, Rappaport L. Extracellular matrix and growth factors during heart growth. Heart Fail Rev. 2000; 5:119-130.

42. Birla RK, Borschel GH, Dennis RG. In vivo conditioning of tissue-engineered heart muscle improves contractile performance. Artif Organs. 2005;29:866-875.

43. Birla RK, Borschel GH, Dennis RG, et al. Myocardial engineering in vivo: formation and characterization of contractile, vascularized three-dimensional cardiac tissue. Tissue Eng. 2005; 11:803-813.

44. Borschel GH, Dow DE, Dennis RG, et al. Tissue-engineered axially vascularized contractile skeletal muscle. Plast Reconstr Surg. 2006;117:2235-2242.

45. Carrier RL, Papadaki M, Rupnick M, et al. Cardiac tissue engineering: cell seeding, cultivation parameters, and tissue construct characterization. Biotechnol Bioeng. 1999;64:580-589.

46. Hamada K, Oike Y, Takakura N, et al. VEGF-C signaling pathways through VEGFR-2 and VEGFR-3 in vasculoangiogenesis and hematopoiesis. Blood. 2000;96:3793-3800.

47. Vouyouka AG, Powell RJ, Ricotta J, et al. Ambient pulsatile pressure modulates endothelial cell proliferation. J Mol Cell Cardiol. 1998;30:609-615.

48. Prabha S, Verghese S. Existence of proviral porcine endogenous retrovirus in fresh and decellularised porcine tissues. Indian J Med Microbiol. 2008;26:228-232.

Address correspondence to: Ketaki Methe, $M S$

Laboratory for Transplantation and Regenerative Medicine Sahlgrenska Science Park Medicinaregatan 8A, 2nd Floor Gothenburg, $S$-413 46 Sweden

E-mail: ketaki.methe@gu.se

$\begin{aligned} & \quad \text { Abbreviations Used } \\ & \text { BMP-9 }=\text { bone morphogenic protein } \\ & \text { D/W }=\text { distilled water } \\ & \text { DAPI }=4^{\prime}, 6 \text {-diamidino-2-phenylindole, dihydrochloride } \\ & \text { DC }=\text { decellularized } \\ & \text { ECM }=\text { extracellular matrix } \\ & \text { EGF }=\text { epidermal growth factor } \\ & \text { FGF }=\text { fibroblast growth factor } \\ & \text { GAG }=\text { glucosaminoglycans } \\ & \text { G-CSF }=\text { granulocyte colony stimulating factor } \\ & \text { HGF }=\text { hepatocyte growth factor } \\ & \mathrm{IL}=\text { interleukin } \\ & \text { PBS }=\text { phosphate buffered saline } \\ & \text { r.t }=\text { room temperature } \\ & \text { SDC }=\text { sodium deoxycholate } \\ & \text { SEM }=\text { scanning electron microscopy } \\ & \text { TEM }=\text { transmission electron microscopy } \\ & \text { VEGF }=\text { vascular endothelial growth factor } \\ &\end{aligned}$

